\title{
PINTURA DELS PAÏSOS BAIXOS EN EL MOBAT (XILE)
}

\author{
Albert Ferrer Orts \\ Universidad Autónoma de Chile
}

\begin{abstract}
Resum: Traiem a la llum la col-lecció de pintura flamenca i holandesa que es conserva en el MOBAT a Xile, un dels espais culturals més reeixits del país clausurat des dels inicis del 2010. Un conjunt d'obres gairebé desconegudes fins ara que agrupem i donem un major sentit com a pintures de temàtica religiosa, mitològica o de gènere d'autors coneguts i d'altres d'anònimes.
\end{abstract}

Paraules clau: MOBAT/ Xile/ pintura flamenca i holandesa/ llenços i coures/ segles XVII-XIX.

\section{Dutch painting in the MOBAT}

Abstract: Exposing the collection of Flemish and Dutch painting preserved in MOBAT (Chile), one of the most successful cultural spaces of this country closed since the beginning of 2010. A set of previously almost unknown works until nowadays that we group and give a greater sense of how to paint religious and mythological themes or known authors' genre and others anonymous.

Key words: MOBAT / Chile / Flemish and Dutch painting / brass and canvas / XVIIth-XIXth centuries.

El Museo O'Higginiano y de Bellas Artes de Talca (MOBAT), ubicat en l'anomenada "Casa de la Independencia", és un dels espais museístics més reeixits de Xile, malgrat que des de fa quatre anys roman clausurat pels efectes que va causar-li el terratrèmol esdevingut el 2010. Es troba situat a la capital de la VII Regió, el Maule, concretament en una cèntrica i antiga casona d'aparença colonial declarada Monument Històric Nacional per mitjà del Decret del Ministeri d'Educació núm. 1.749 de 26.VII.1971, amb el núm. 64 (Montandon-Pirotte, sa, fitxa 99), i depèn de la Dirección de Archivos, Bibliotecas y Museos (DIBAM), estructurant-se al voltant de dos patis i un hortet a què s'hi afegí en una de les cantonades un nou edifici que serveix com a dipòsit, biblioteca i oficines. Tanmateix, el museu no ha romàs sempre en aquest lloc (González, 2014, sp) [figura 1].

Immersos en la commemoració del seu cinquantè aniversari en l'actual ubicació, que se celebra aquest mateix any, cal ressenyar que, en la seua doble vessant de museu d'història $\mathrm{i}$ de belles arts, conserva un considerable nombre de peces que van des d'objectes $\mathrm{i}$ documents pròpiament històrics fins a escultures, dibuixos, fotografies i pintures ${ }^{1}$.

Des d'un temps ençà ha cridat la nostra atenció la seua col·lecció pictòrica, composada fonamentalment per obres d'autors xilens i europeus, sent del nostre particular interès la d'aquests darrers en què es troben representades diverses nacionalitats com l'alemanya, belga, danesa, espanyola, francesa, holandesa, italiana i sueca (Ferrer, en premsa); en par-

Data de recepció: 30 d'abril de 2014 / Data d'acceptació: 22 de juliol de 2014.

1 Agraeix sobre manera a N'Alejandro Morales Yamal i En Gonzalo Olmedo Espinoza, director i conservador del MOBAT respectivament, la seua predisposició perquè pogués realitzar el meu treball i les facilitats que en tot moment em van proporcionar. 


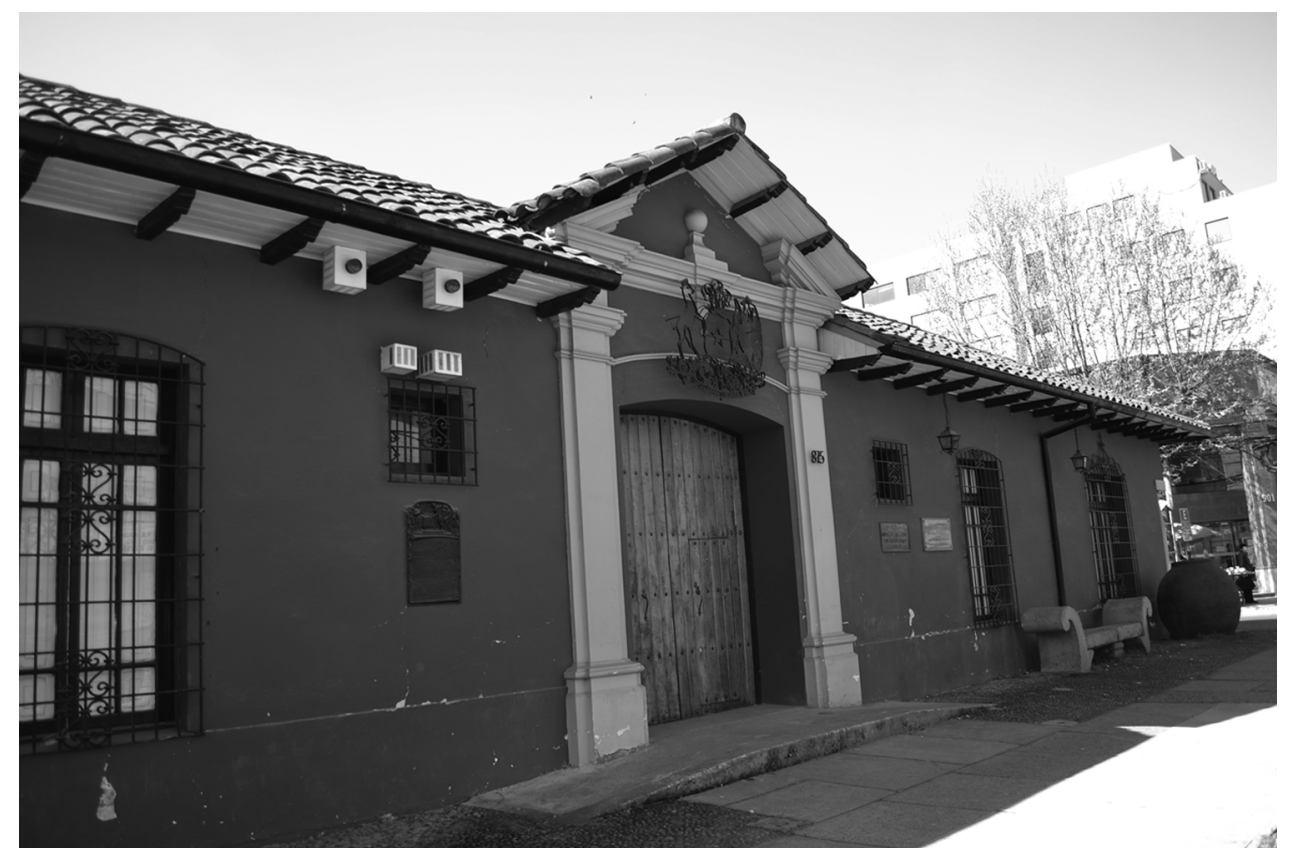

Fig. 1. MOBAT. Fotografia de MSMT.

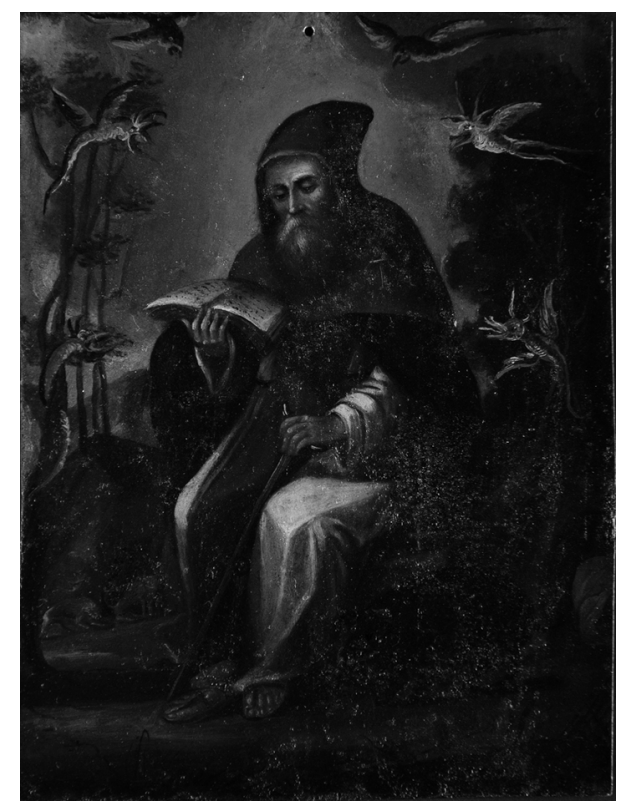

Fig. 2. "Temptacions de sant Antoni Abat", anònim. Fotografia de Viviana Rivas, CNCR-DIBAM. 
ticular la produïda als Països Baixos per la seua qualitat, variada temàtica i diversitat d'autors que la composen. Així doncs, trobem obres dels belgues Willem van Herp (16141677) i Jan Frans Eliaerts (1761-1848), com també dels neerlandesos Albert Cuyp (16201691), Andreas Schelfhout (1787-1870), Henri van Wijk (1833-?), Anton Mauve (18381888) i, potser, A. d'Haemer (actiu en 1871). Una nòmina de pintors d'interès per quant el seu llegat artístic és bastant desconegut a hores d'ara perquè pràcticament no s'ha estudiat ni tampoc s'ha difós com cal.

Pel que fa als Països Baixos del sud, trobem, com s'ha dit, cinc obres que atribuïm Van Herp o que estan molt pròximes al seu quefer, les quals estan pintades a l'oli sobre planxes de coure, encara que només una d'elles apareix signada per l'autor. Totes en l'òrbita dels grans mestres flamencs com Rubens, Van Dyck o els Teniers (el Vell i el Jove). Es tracta de dues de menudes que representen "Les temptacions de sant Antoni Abat" (oli sobre coure, 24'7 x 18'7 cm) i "Maria Magdalena penitent" (oli sobre coure, 22 x $17 \mathrm{~cm}$ ) que, potser, formaren parella, i altres tres de majors dimensions: "Paràbola del banquet de bodes" (oli sobre coure, 63 x $78 \mathrm{~cm}$ ), les "Obres de la Misericòrdia" (oli sobre coure, 56 x 72 '5 cm) (Ferrer-Ferrer-Olmedo, en premsa) i "Els deixebles d'Emaús" (oli sobre coure, $52 \times 71 \mathrm{~cm}$ ), aquesta darrera en procés de restauració quan redactàvem aquestes línies.

\section{Les temptacions de sant Antoni Abat [figura 2]}

(Registre 7-27, inventari 1.27: "L'ermità"; llegat d' Eusebio Lillo, 1910)

El sant apareix -tal com relata Santiago de la Vorágine en la Llegenda Daurada- assegut en plena naturalesa amb el seu hàbit, mentre en una mà sosté un llibre i en l'altre un bastó. Està immers en la lectura malgrat les temptacions que, en forma d'estranyes criatures, l'envolten. Un tema molt popular i tractat en nombroses ocasions pels creadors d'època medieval i moderna atesa la vinculació del sant amb l'agricultura i el bestiar. La qualitat del seu semblant és innegable i el tractament del paisatge és superficial, no així la figura del personatge ja que la seua fisonomia ix sobre dimensionada del contrast.

La pintura té un orifici en la part superior, encara que està guarnida per un marc que ens sembla original (tipus flammenleisten), tal com esdevé en la de Maria Magdalena.

\section{Maria Magdalena penitent [figura 3]}

(Registre 7-50, inventari 1.50: "Magdalena en el desert"; llegat d'Eusebio Lillo, 1910)

La Magdalena apareix com a penitent amb els atributs que se li associen com una eremita. Se la representa jove i bella mentre agafa un pany blanc, signe indiscutible que l'assenyala com a testimoni de la passió i mort de Jesucrist com també de la seua resurrecció. Altres símbols que formen part d'una naturalesa morta l'acompanyen, com uns llibres, la calavera, un flagell i un ampolla amb perfum de subtil elegància.

El paisatge es resumeix en un cau en penombra en què destaca una potent flama celestial que ungeix la protagonista i, alhora, contribueix a destacar la seua llarga cabellera com el seu cos i tors seminu. En aquesta composició, els deutes amb Rubens són més que evidents, especialment el seu intens cromatisme i la qualitat de la seua execució fins els més mínims detalls. 


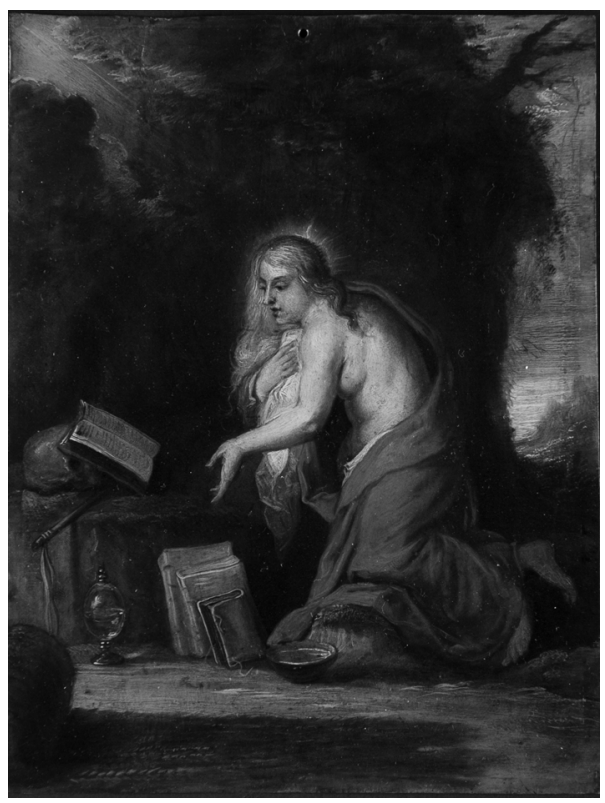

Fig. 3. "Maria Magdalena penitent", anònim. Fotografia de Viviana Rivas, CNCR-DIBAM.

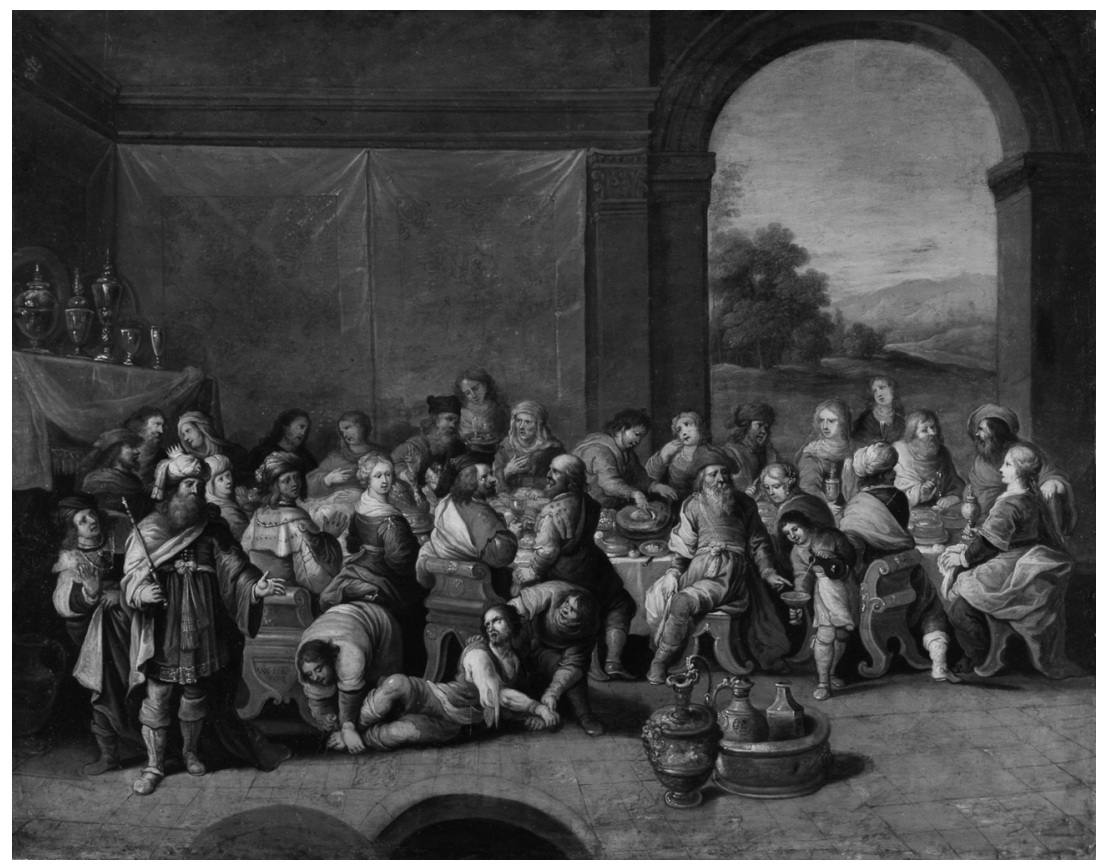

Fig. 4. "Paràbola del banquet de boda", Van Herp. Fotografia de Viviana Rivas, CNCR-DIBAM. 
Paràbola del banquet de boda [figura 4]

(Registre 7-241, inventari 1.238: "Càstig del traïdor")

En l'ampli saló d'un palau obert a l'exterior mercè una àmplia arcada de mig punt rebaixada des que es beslluma un bucòlic paisatge campestre es desenrotlla un banquet de boda en què es distingeixen quatre grups de comensals entre d'altres escenes individualitzades. L'escena principal la forma un monarca vestit a la moda oriental, tal qual alguns personatges de l'entorn, rebent consell a l'hora d'ordenar nuar i tancar a un convidat amb roba inapropiada per a l'esdeveniment.

El relat està inspirat tant en els Evangelis canònics de sant Mateu (Mt 22, 1-14) i sant Lluc (Lc 14, 15-24), com en l'apòcrif de sant Tomàs (Tm 64), en què Jesús conta la Paràbola del banquet de boda, i està signada: "VAN HERP".

\section{Obres de la Misericòrdia [figures 5 i 6]}

(Registre 7-5, inventari 1.5: “Assotats per la fam”; llegat d'Eusebi Lillo, 1910)

Reflectides en una de les planxes de majors dimensions apareixen representades les set obres corporals, és a dir, visitar i cuidar els malalts, donar de menjar al famolenc, donar de beure a l'assedegat, donar refugi al pelegrí, vestir al nu, visitar i redimir els captius i soterrar els difunts; així com una de les espirituals: pregar a Déu pels vius i els difunts. Totes elles inspirades en Mt 6, 2-4, Mt 25, 31-46, Tb 4, 5-11 i Si 17, 22. Crida l'atenció que tots aquests preceptes cristians apareixen representats mitjançant una bigarrada composició en un escenari obert i nuvolat tan característic del nord d'Europa, tal qual feren també els Teniers, pare i fill. D’aquest darrer es conserva un oli sobre coure en el Museu del Louvre bastant semblant.

Atribuïda a Eliaerts es troba una pintura de mitjanes dimensions titulada "Naturalesa morta, raïm i groselles" (oli sobre fusta, 34,50 x 41,50 cm, marc inclòs), una composició ben afí a l'òrbita creativa de l'artista flamenc, tan familiaritzat amb aquest gènere tan popular en la pintura nòrdica des del segle XVI (Ferrer, en premsa).

\section{Naturalesa morta, raïm i groselles ${ }^{2}$ [figura 7]}

(Registre 7-121, inventari 1.121)

Es tracta d'un bodegó composat per penjolls de raïm blanc i rosat entre petites i delicades flors i mores vermelles entre fullam, mentre una papallona es posa al damunt. No cap dubte de l'habilitat del pintor per a fer quasi tàctil l'escena retratada, fins i tot exuberant el que pot esdevenir una composició ben quotidiana, per altra banda tan afí als pintors d'aquelles terres baixes costaneres al Mar del Nord.

Pel que fa a la pintura holandesa pròpiament dita, tan ben representada com la dels seus veïns del sud, trobem en primer lloc un quadre de possible atribució a Cuyp amb el títol "La infantesa de Silè" (oli sobre llenç, 113,50 x 86,50 cm), una obra amb temàtica mitològica necessitada d'una intervenció que li torne l'aspecte cromàtic original (Ferrer, en premsa) i que, en altre temps fou posada en relació amb la pintura bolonyesa (Vidor, 1930, 96). leg.

2 Exposada en la mostra El vino en la pintura chilena, Rancagua, 1997, de què no hi consta cap catà- 


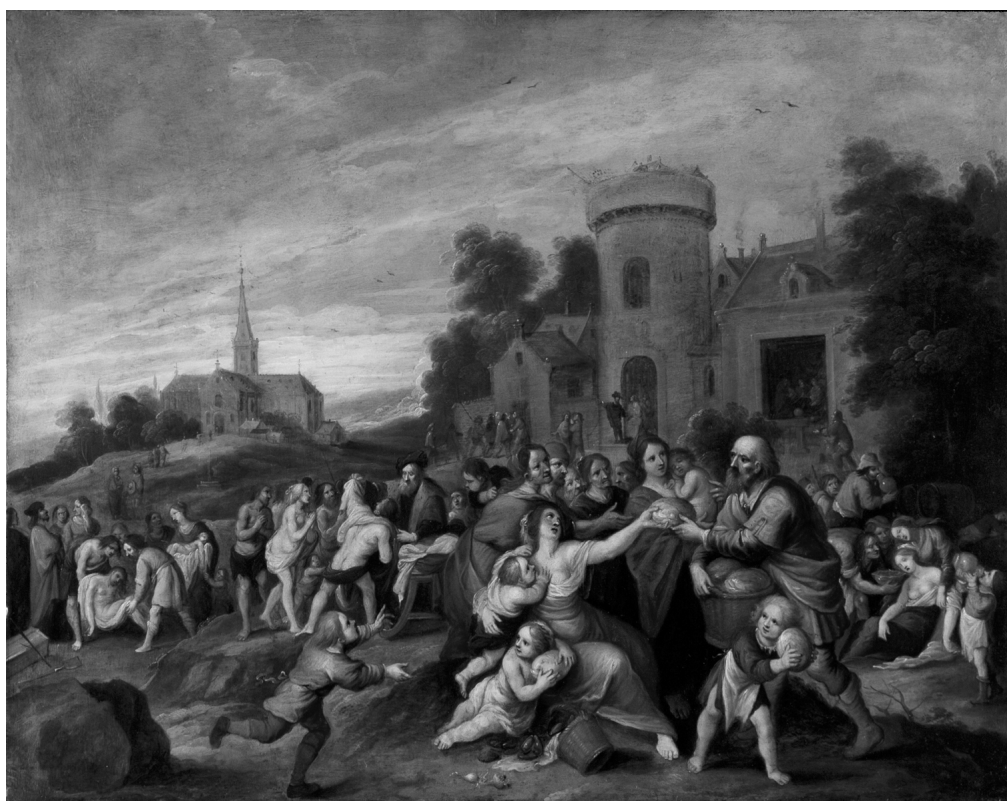

Fig. 5. "Obres de la Misericòrdia", anònim. Fotografia de Viviana Rivas, CNCRDIBAM.

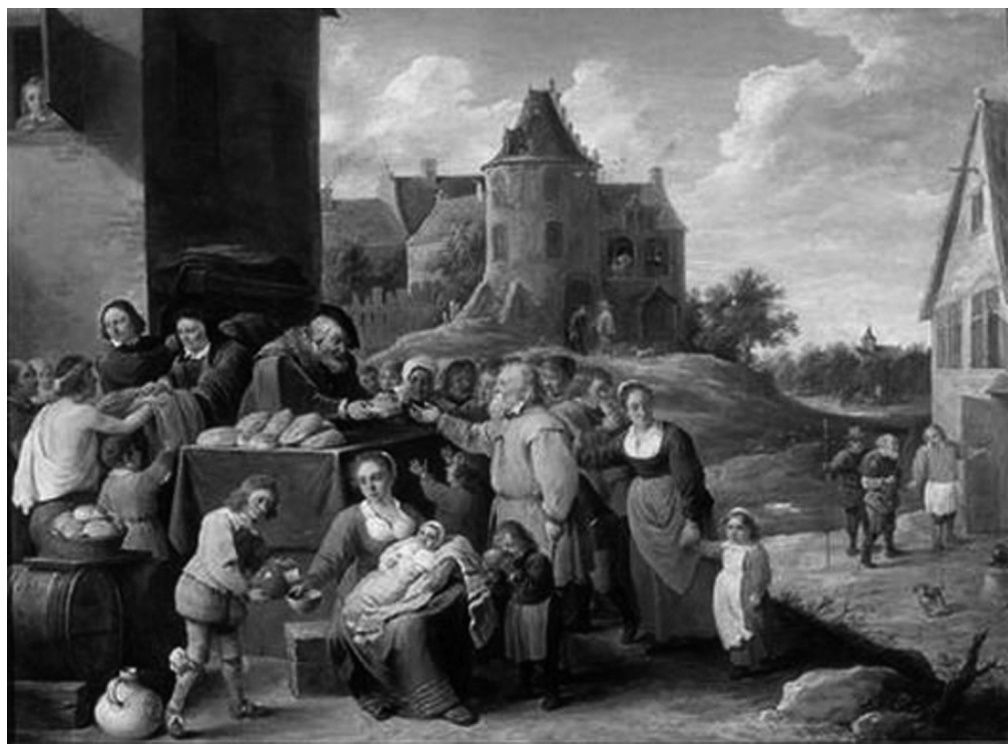

Fig. 6. David Teniers el Jove, "Obres de la Misericòrdia" (oli sobre coure, 57 x 77 cm), Museu del Louvre. 


\section{La infantesa de Silè [figura 8]}

(Registre 7-43, inventari 1.43, donació de Marcos Segundo Maturana)

Segons la mitologia, Silè fou un sàtir sovint representat vell i gros com a déu menor de l'embriaguesa, pare adoptiu, preceptor i company de Dionís. Però a diferència dels altres sàtirs tenia cos humà, orelles d'ase i cua de cavall. Entre els seus trets definitoris destacava per la lletjor, la calvície i una fisonomia en què ressaltaven els seus llavis i nas carnosos. Característiques que s'endevinen tant en Silè gitat al bressol i embolcallat com a nounat com en els altres sàtirs que l'acompanyen, ja que tots tres comparteixen semblant aparença física. La gràcia dels retratats, sobretot en captar el pintor la tendresa de la infantesa, així com la qualitat de la pinzellada, alhora pastosa i fluïda, juntament amb una paleta cromàtica càlida, no cap dubte que ens parlen d'un bon pintor en l'òrbita dels holandesos i, per descomptat, de Cuyp.

L'escena també aporta a l'espectador la qualitat dels teixits i els seus clarobscurs, les naturaleses mortes i el típic paisatge nòrdic que s'entreveu a un extrem. Pintura que està molt necessitada, com dèiem, d'una intervenció que puga restituir-li el seu llustre primigeni i precisar més la seua autoria.

De Schelfhout es conserva igualment un "Paisatge" (oli sobre llenç, 68,50 x $52 \mathrm{~cm}$ ), en perfectes condicions de conservació (Muñoz Zárate, 2001, 34-35 i Ferrer, en premsa).

\section{Paisatge [figura 9]}

(Registre 7-228, inventari 1.225)

Una obra típicament holandesa en tant en quant hi apareix una mena de granja formant part d'un paisatge obert de potents celatges, mentre animals d'estable pasturen a la vora d'un rierol en escenari certament idíl-lic. El llenç està signat en la zona inferior esquerra: "A. Schelfhout".

Van Wijk és un dels altres pintors neerlandesos dels que el museu maulí té obra, un consumat paisatgista, particularment de marines, ben conegut. "Marina" (oli sobre llenç, 51,50 x $32 \mathrm{~cm}$ ) i "Marina amb velers" (oli sobre llenç, 51 x $32 \mathrm{~cm}$ ) són dues peces de petites dimensions que mostren un excepcional domini de la tècnica en benefici d'una notable qualitat final (Muñoz Zárate, 2001, 42-43 i Ferrer, en premsa).

Marina [figura 10]

(Registre 7-243, inventari 1.240)

Es tracta d'un quadre de gènere marí, tan apreciat per l'autor, en què apareixen alguns velers tant en primer com en segon plànol mentre que a un costat ho fan una sèrie de pescadors. El paisatge es difumina cap el fons per mitjà de boirines i, pel reflex del sol en l'aigua, la llum sembla o bé matinal o bé crepuscular. Una escena habitual entre els paisatgistes holandesos. Signat en l'extrem inferior esquerre: "Wijt".

\section{Marina amb velers [figura 11]}

(Registre 7-242, inventari 1.239)

Atenent que aquesta obra té quasi les mateixes mesures que l'anterior, així com la versemblança de les temàtiques representades, doncs es pot pensar que ambdues pogueren haver format parella, no cap dubte que Van Wijk s'especialitzà en pintar marines a 


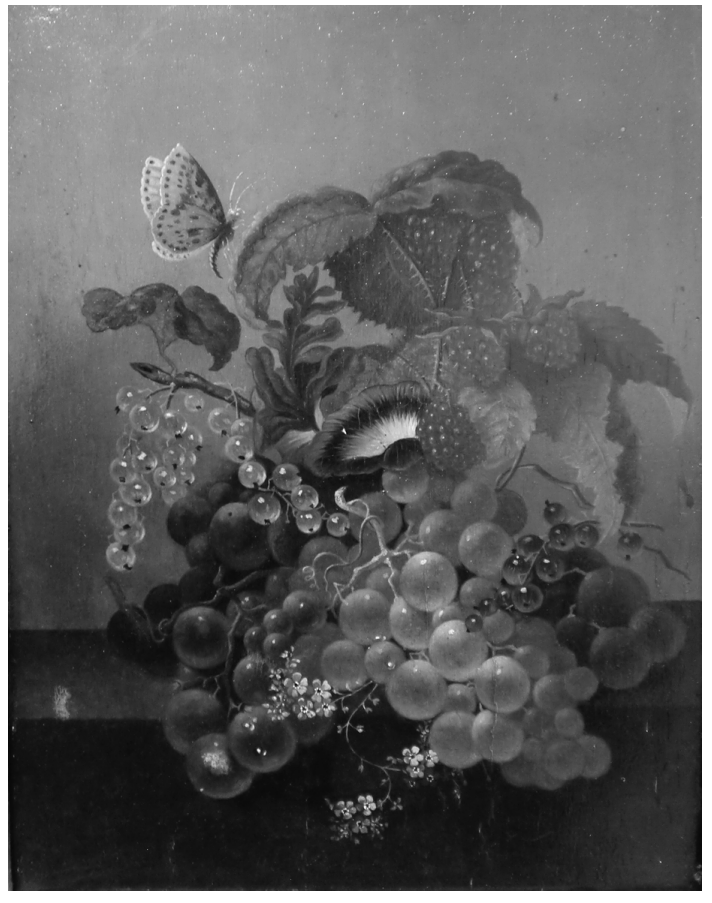

Fig. 7. "Naturalesa morta, raïm i groselles", atribuïda a Eliaerts. Fotografia d'AFO.

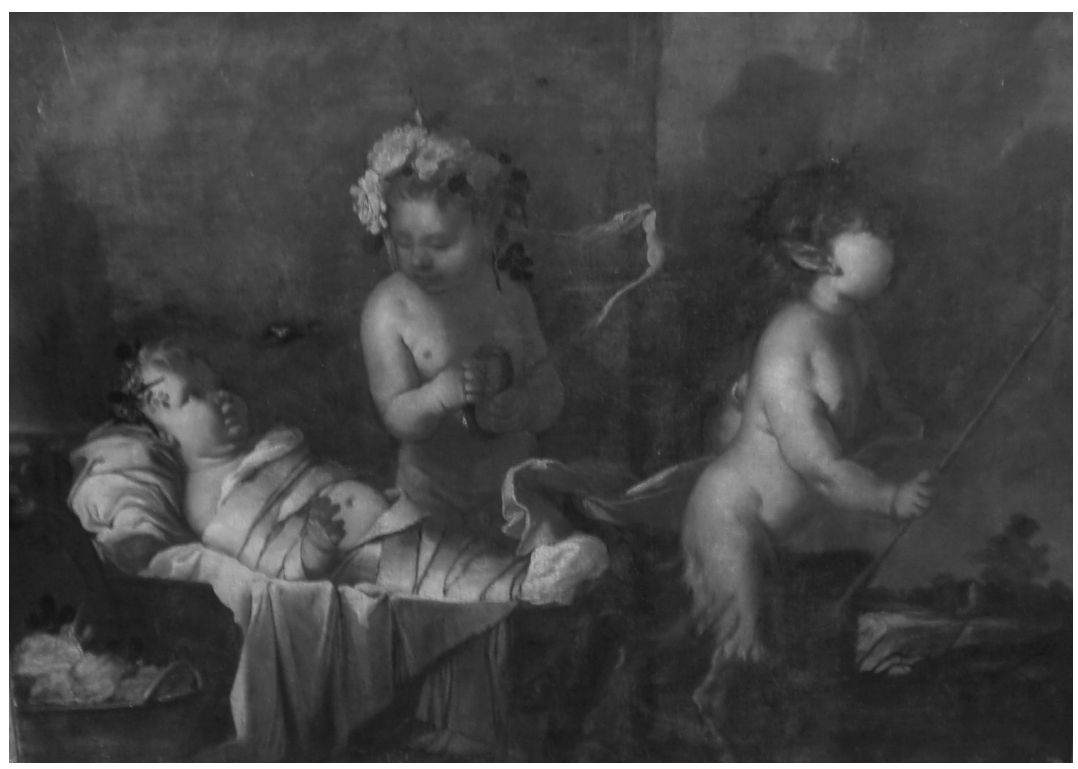

Fig. 8. "La infantesa de Silè", atribuïda a Cuyp. Fotografia d'AFO. 


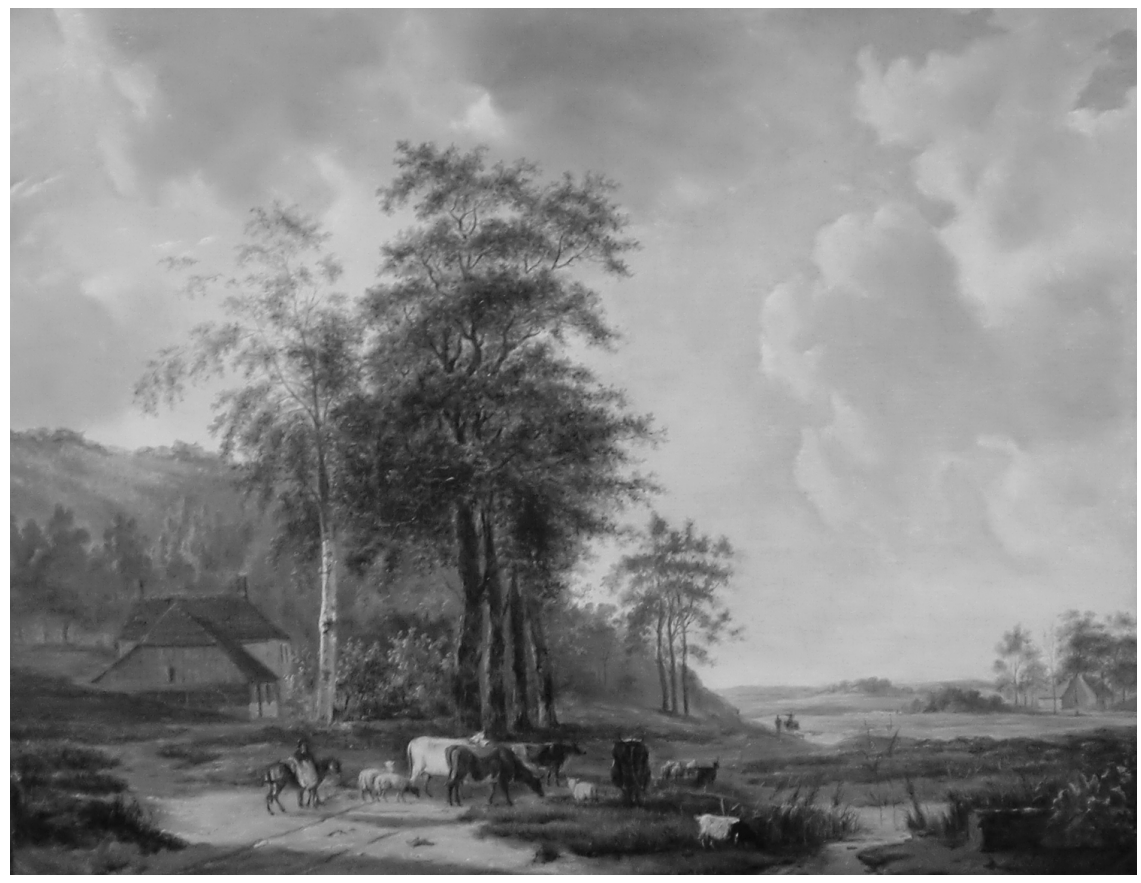

Fig. 9. "Paisatge", Schelfhout. Fotografia d'AFO.

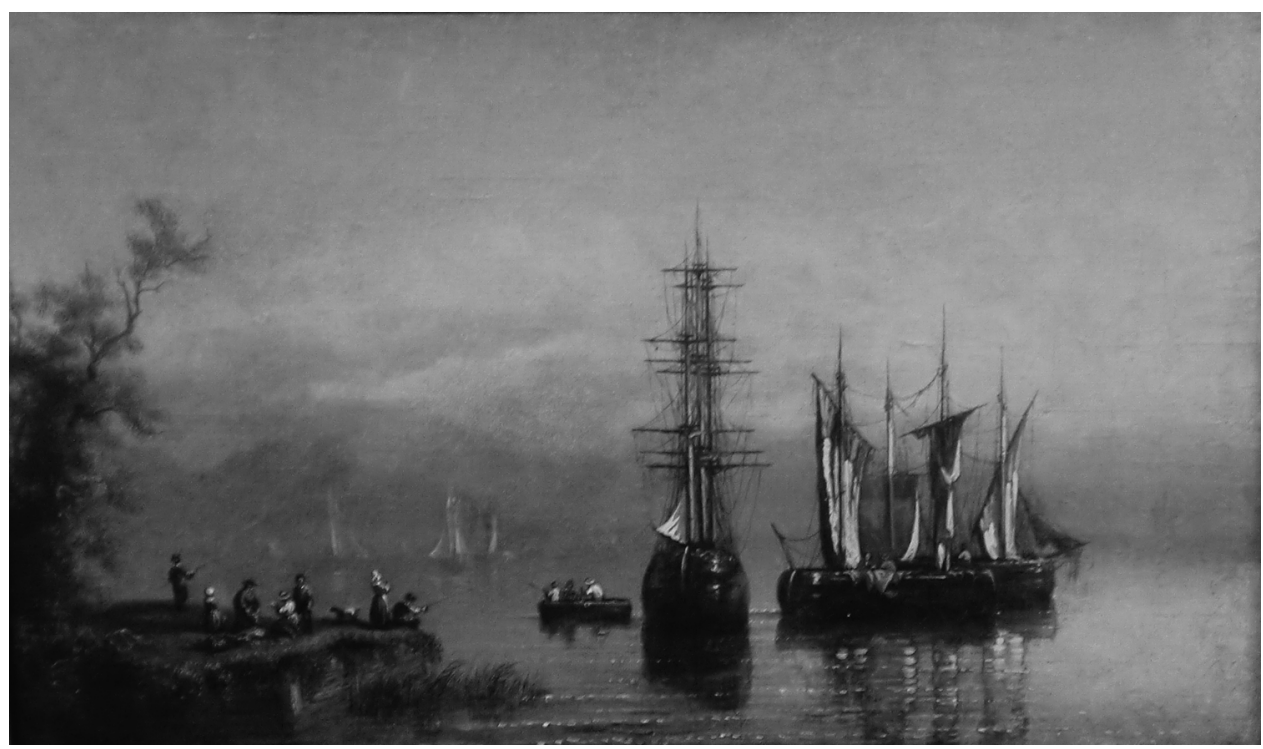

Fig. 10. "Marina", Van Wijk. Fotografia d'AFO. 
determinades hores del dia. Creacions que, com altres gèneres pictòrics, varen tindre una notable acollida entre la clientela burgesa per tal de decorar les estances dels seus habitatges. Signat en l'extrem inferior dret: "Wijt".

Un altre representat d'aquesta escola de qui hi ha obra en el MOBAT és Mauve, autor del segle XIX que també es dedicà a representar paisatges rurals sobre superfícies de ceràmica, com la produïda a Rozenburg den Haag. En aquest cas en particular trobem "Paisatge amb bovins" (oli sobre porcellana, 16,30 x 26,80 cm), un tipus de representació molt habitual en la seua producció i en la d'altres col·legues contemporanis (Ferrer, en premsa).

\section{Paisatge amb bovins [figura 12]}

(Registre 7-170, inventari 1.167)

Mauve utilitza sovint porcellana de Rozenburg den Haag (Holanda) per a les seues petites realitzacions de gènere campestre amb bovins pastant plàcidament en els prats i boscos neerlandesos. La minuciosa tècnica a l'oli ix reforçada per la polida superfície del material ceràmic, conferint-li una pàtina tan lluenta com vívida. Signat en la part inferior esquerra: "N. A MAUVE".

El darrer artista plàstic que, pensem, potser d'aquesta nacionalitat es tracta D'Haemer, mitjançant dos petites pintures sobre fusta a l'oli signades amb temes militars que segurament farien parella: "El bandera del castell" (registre 7-115, inventari 1.115; 15 x $21 \mathrm{~cm}$ ) i "El corneta del castell" (registre 7-116, inventari 1.116; 15 x $20 \mathrm{~cm}$ ), sengles pertanyents al llegat d'Eusebio Lillo (1910). Pintures que a l'hora de redactar aquest treball es trobaven en procés de restauració per la DIBAM a Santiago de Xile, per la qual cosa no les hem pogut estudiar com haguera estat el nostre desig [figures 13 i 14].

Sense una autoria definida o més difusa i una procedència també incerta hi ha un parell d'obres que podrien estar en l'òrbita directa o indirecta dels obradors dels Països Baixos tant per la temàtica representada, les tècniques emprades com els suports utilitzats per a realitzar-les. Les relacionem a continuació: es tracta d'una "Coronació d'espines" (oli sobre coure, 60 x $53 \mathrm{~cm}$ ), còpia de la mateixa obra de Van Dyck i que apareix com a anònim quiteny del segle XVIII -igualment pertanyent al llegat de Lillo-, i d'un "Sant Ignasi de Loiola" (oli sobre coure, 18 x 13,5 cm), aquesta darrera amb el marc original barroc potser de finals del Sis-cents.

\section{Coronació d'espines ${ }^{3}$ [figures 15, 16 i 17]}

(Registre 7-20, inventari 1.20: “Cristo flagelado”, llegat d'Eusebio Lillo, 1910)

L'obra és una còpia a menor escala i en posició canviada de la cèlebre obra homònima d'Anton van Dyck en el Museu del Prado (1618-1620) i que el pintor flamenc regalà a Rubens (Ayala, 1995, 174-175). La composició es basa en els Evangelis de sant Mateu (Mt 27, 29) i sant Marc (Mc 17, 17) i mostra a Jesucrist sent coronat després d'haver estat flagel·lat pels soldats romans, els quals l'envolten mentre li profereixen improperis i li posen en les mans la vara com a ceptre. L'anònim autor del coure segueix en línies generals fil per randa el geni creatiu de Van Dyck, segurament inspirant-se en un gravat o una estampa. Cal recordar que d'aquest tema Van Dyck tenia una altra versió perduda, potser més sem-

\footnotetext{
${ }^{3}$ Cortés $(2009,95)$.
} 


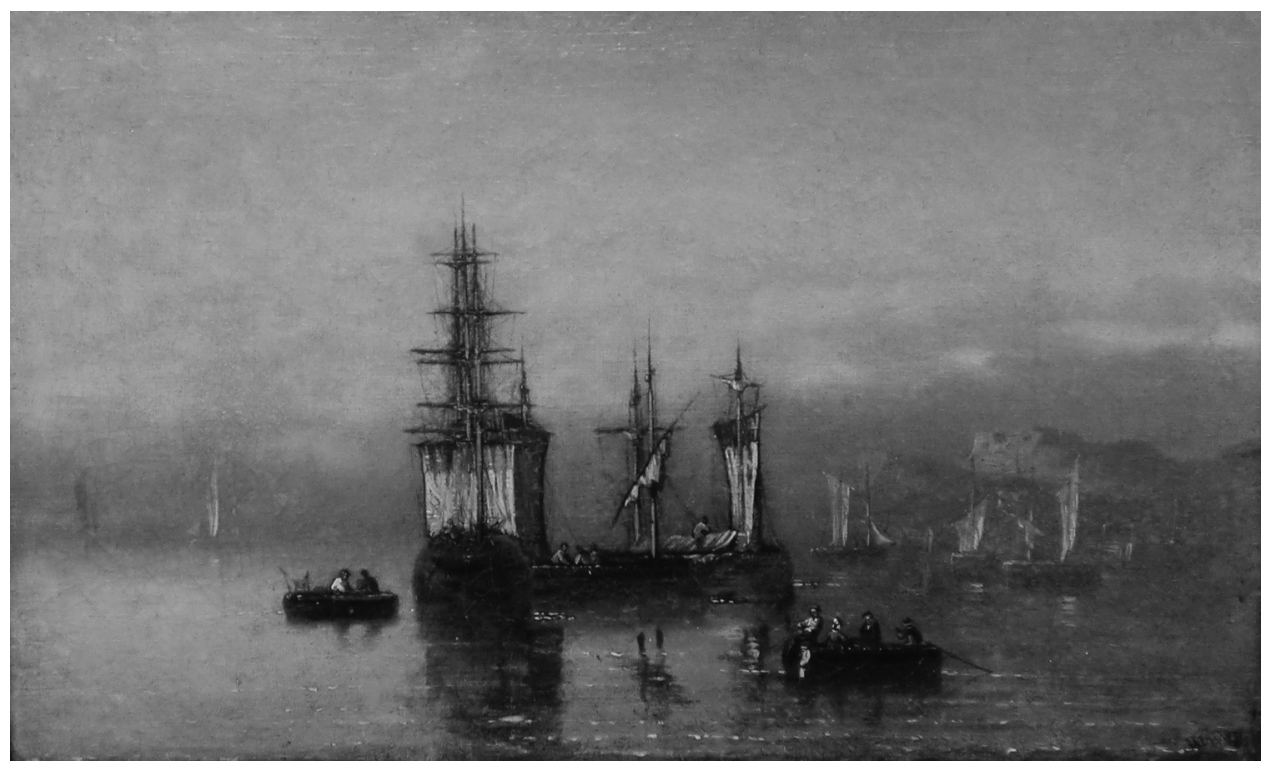

Fig. 11. "Marina amb velers", Van Wijk. Fotografia d'AFO.

Fig. 12. "Paisatge amb bovins", Mauve. Fotografia d'AFO.

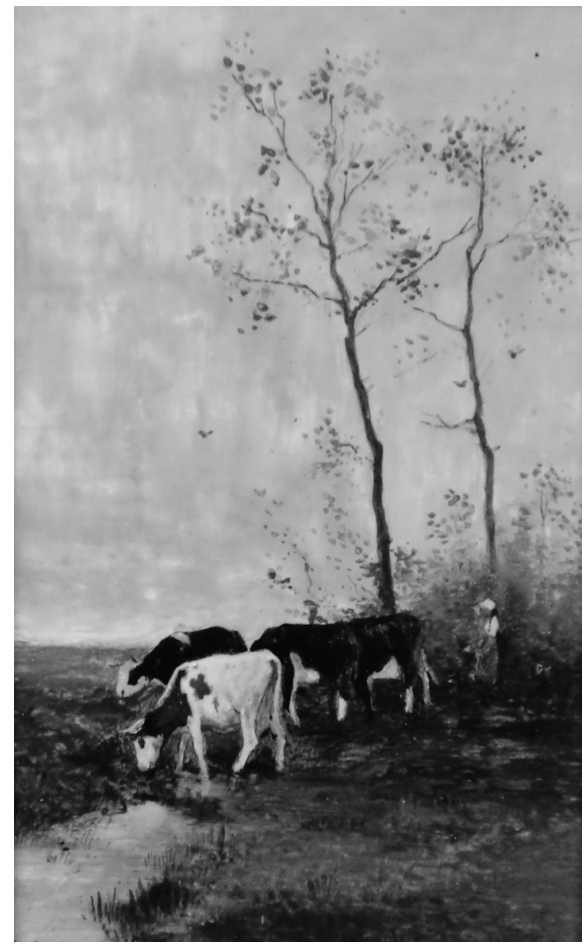




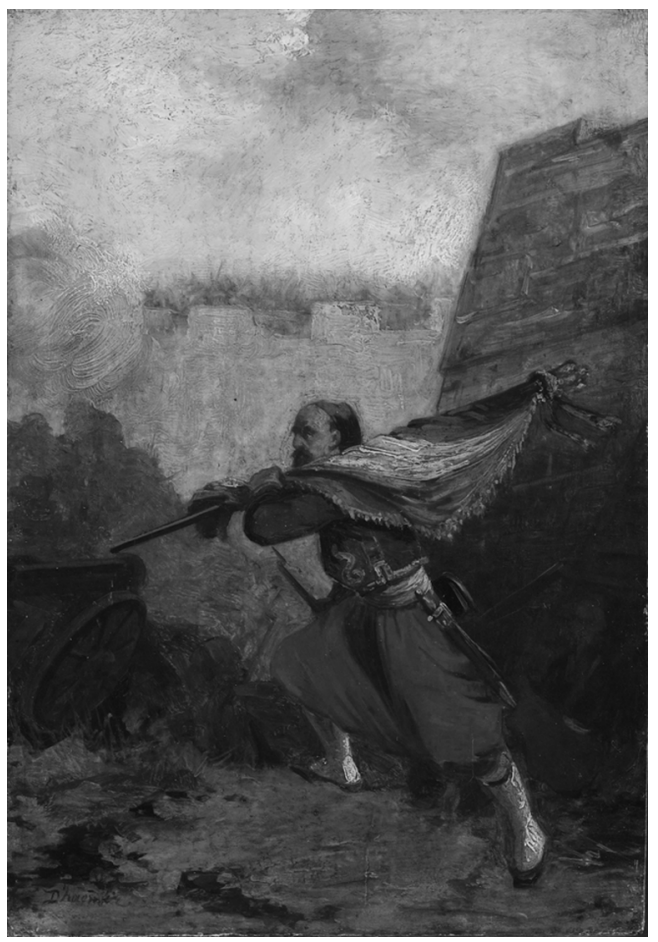

Fig. 13. "El bandera del castell", A. d'Haemer. Fotografia de Viviana Rivas, CNCRDIBAM.

Fig. 14. "El corneta del castell", A. d'Haemer. Fotografia de Viviana Rivas, CNCRDIBAM.

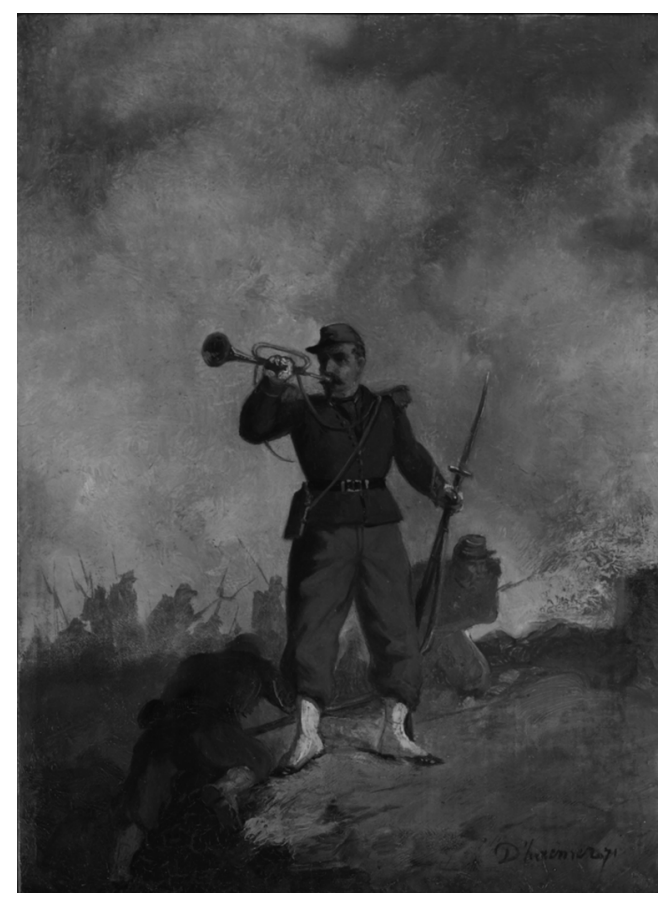

Saitabi. Revista de la Facultat de Geografia i Història, 64-65 (2014-2015), pp. 167-181 ISSN 0210-9980 D0I: 10.7203/saitabi.64.7261 @다요 


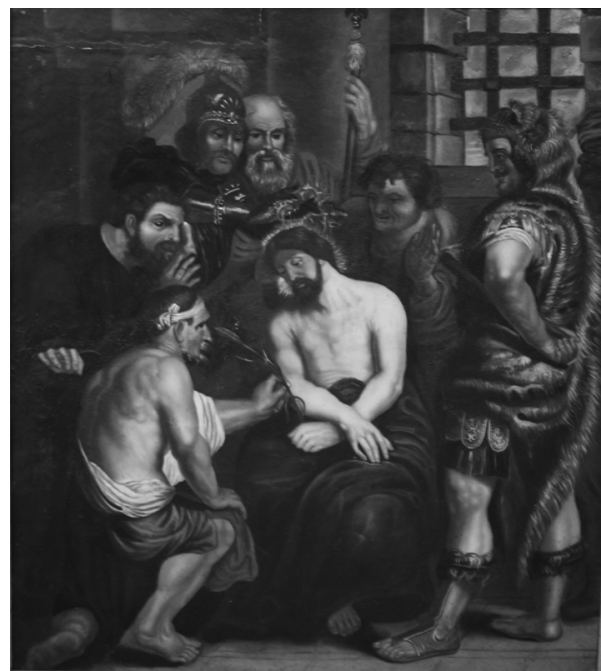

Fig. 15. "Coronació d'espines", anònim. Fotografia de PMV.

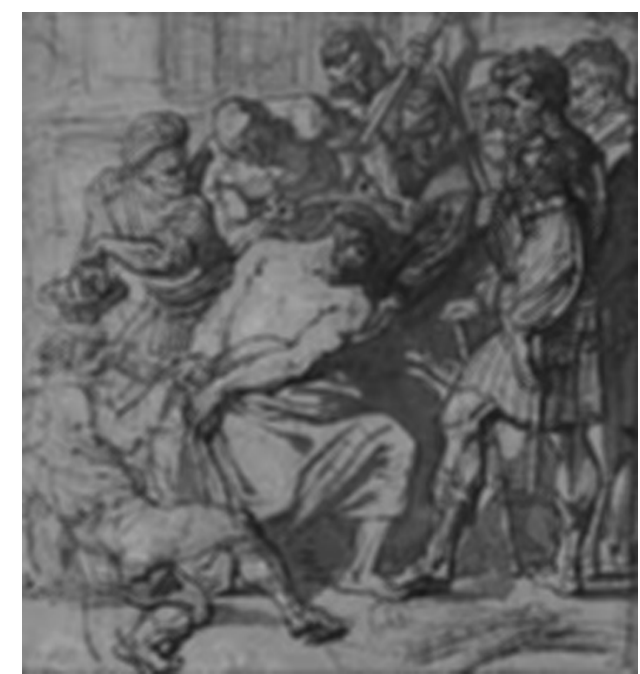

Fig. 16. Anton van Dyck, "Coronació d'espines". Amsterdam Historisch Museum.
Fig. 17. Anton van Dyck, "Coronació d'espines". Museu del Prado.

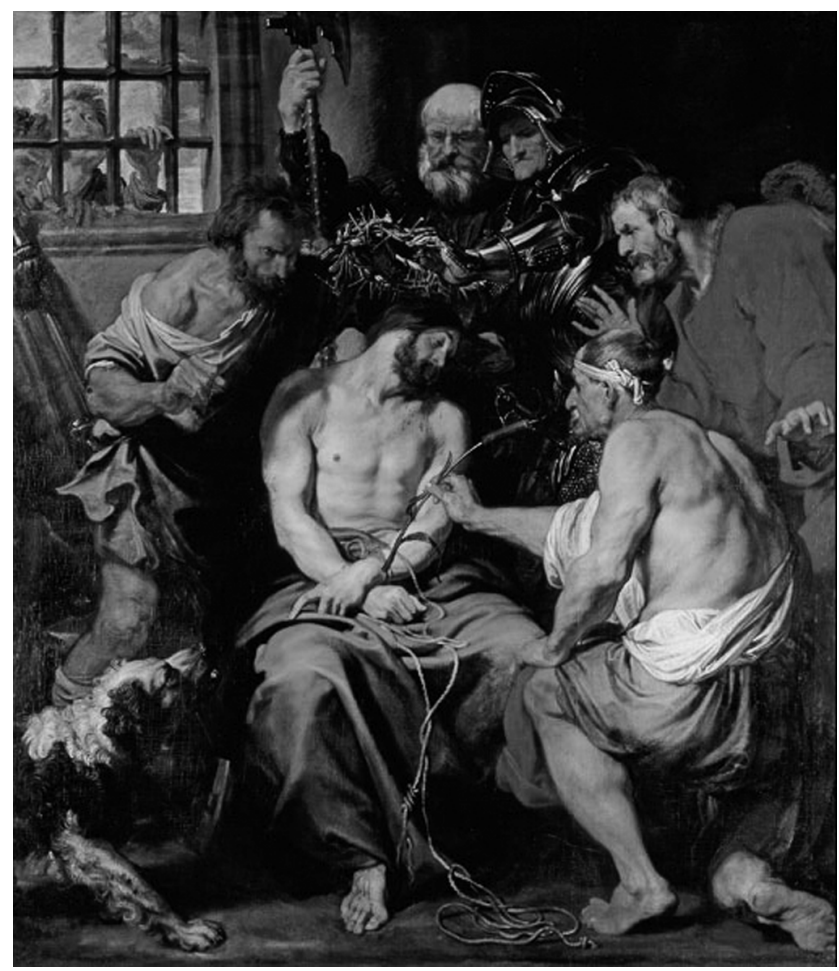

Saitabi. Revista de la Facultat de Geografia i Història, 64-65 (2014-2015), pp. 167-181 @) $(\Theta \Theta$ ISSN 0210-9980 D0I: 10.7203/saitabi.64.7261 


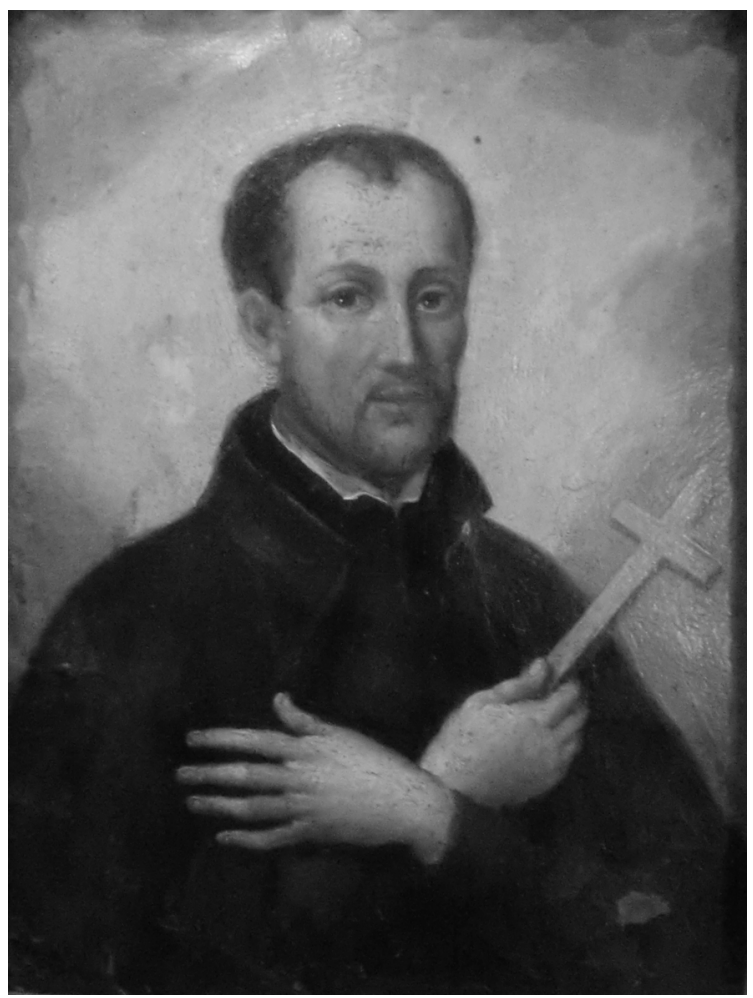

Fig. 18. "Sant Ignasi de Loiola", anònim. Fotografia d'AFO.

blant a l'obra que analitzem en què hi apareixen més personatges, composició molt pròxima al dibuix preparatori que d'aquella pintura es conserva a l'Amsterdam Historisch Museum (18,6 x 17,6 cm), realitzat en idèntica cronologia. La planxa té una particularitat que crida l'atenció, i és que el seu vèrtex superior dret presenta una soldadura per tal de conferir-li a la mateixa la regularitat en tots els seus costats que sembla que no tenia, la qual cosa fa que la capa pictòrica no siga del tot uniforme i la seua qualitat global resulte afectada. En la catalogació del museu hi apareix com a anònim de Quito, circumstància que podria ser factible atenent que al virregnat del Perú hi havia una activa comunitat artística que abastia el mercat interior i les necessitats artístiques de territoris més allunyats com és el cas de Xile. Pel que fa a la seua datació, pensem que pogué ser executada en les acaballes del segle XVII.

\section{Sant Ignasi de Loiola ${ }^{4}$ [figura 18]}

(Registre 7-78, inventari 1.78)

És la més modesta de totes les planxes de coure que hi han en el museu de Talca, la qual representa el bust del sant jesuïta fundador de l'Orde mentre abraça una creu, encara

\footnotetext{
${ }^{4}$ Exposada en la mostra Retratos y figura humana, Santiago, 1984, de què no hi consta cap catàleg.
} 
que també podria representar ben bé sant Francesc de Borja com a decidit impulsor de l'evangelització de les terres americanes; obra que igualment podria tenir una procedència peruana atenent detalls pròpiament pictòrics. La peça queda guarnida per un ostentós marc barroc, pensem que original, de finals dels segle XVII i presenta petites pèrdues de la pel·lícula pictòrica que reivindiquen una acurada restauració.

En conjunt, ens trobem amb una selecta col·lecció pictòrica que, després de pertànyer a alguns prohoms xilens del Dinou -en particular Eusebio Lillo Robles (Santiago, 18261910), reeixit polític, periodista i poeta, a més d'autor de la lletra de l'himne patri-, fou llegada en la seua major part al Museu Nacional de Belles Arts de la capital austral i, des d'aquest espai cultural, acabà per recalar definitivament al MOBAT. Una sèrie de peces que, en part restaurades recentment, han passat desapercebudes tant al públic com als especialistes fins l'actualitat, per la qual cosa aprofitem l'avinentesa per a donar-les a conèixer.

\section{BIBLIOGRAFIA}

AYALA MALLORY, N. (1995): La pintura flamenca del siglo XVII, Madrid, Alianza Forma.

CORTÉS ALIAGA, G., cur. (2009): Chile mestizo. Tesoros coloniales, Santiago de Chile, Collahuasi.

COUSIÑO TALAVERA, L. (1922): Museo de Bellas Artes. Catálogo general de las obras de pintura, escultura, etc., Santiago de Chile, Soc. Imprenta y Litografía Universo.

FERRER ORTS, A. (en premsa): "Pintura europea en el Museo O'Higginiano y de Bellas Artes de Talca (Chile)".

FERRER ORTS, A., FERRER DEL RÍO, E., OLMEZO ESPINOZA, G. (en premsa): "Unos cobres flamencos del siglo XVII en Talca (Chile)", Atenea.

GONZÁLEZ COLVILLE, J. (2014): “La historia del Museo O’Higginiano”, Manso de Velasco, 1.

MONTANDON, R., PIROTTE, S. (sa): Monumentos Nacionales de Chile, Santiago de Chile, MOP, Dirección de Arquitectura-ICI.

MUÑOZ ZÁRATE, P. (2001): Pintura holandesa en Chile. Siglos XVII-XIX. Dibujos del Rijkmuseum Amsterdam, Santiago, Museo Nacional de Bellas Artes.

VIDOR, P. (1930): "El Museo de Bellas Artes", en T. LAGO; P. VIDOR, El Museo de Bellas Artes, 1880-1930, Santiago de Chile, Universidad de Chile. 
